\title{
Recolocando a autodeterminação na equação? Uma análise da ação coletiva feminista na Europa do Sul*
}

Putting self-determination back into the equation? An analysis of feminist collective action in Southern Europe

\author{
Ana Cristina Santos* \\ Mara Pieri**
}

\begin{abstract}
Resumo - No contexto da Europa do Sul, os direitos das mulheres têm-se confrontado com resistências históricas decorrentes de um legado cumulativo de ditadura, fascismo e catolicismo. Processos mais amplos de modernização desafiaram gradualmente esse legado, com um impacto significativo na mobilização pelos direitos das mulheres. Este artigo examina a ação coletiva feminista na Itália e em Portugal no século XXI, incluindo lutas pró-escolha ligadas ao aborto em Portugal e as mobilizações contra a violência de género na Itália. Em cada contexto, examinamos temas e repertórios dominantes da ação coletiva, mas também fontes de dissidência interna, como as questões da gestação de substituição e do trabalho sexual. Na última seção, sugerimos que a autodeterminação constitui um conceito-chave através do qual os movimentos feministas contemporâneos podem encontrar formas de superar importantes desafios políticos e teóricos emergentes. Palavras-chave: ação coletiva feminista; Europa do Sul; auto-determinação.
\end{abstract}

\begin{abstract}
In the context of Southern Europe, women's rights have been facing historical resistance linked to a legacy of dictatorships, fascism, and Catholicism. Wider processes of modernization have gradually challenged this legacy, causing a significant impact on the mobilization for women's rights. This article explores feminist collective action in Italy and Portugal in the 21st century, including pro-choice struggles connected to abortion in Portugal and the mobilizations against gender-based violence in Italy. In each country dominant themes and repertoires of collective action will be studied,
\end{abstract}

\footnotetext{
* Uma primeira versão deste artigo foi publicada em inglês no livro The Routledge Handobook of Contemporary European Social Movements. Protest in turbulent times, organizado por Cristina Flesher Fominaya e Ramón A. Feenstra (2020). Para esta versão, Santos deseja reconhecer o apoio de duas entidades financiadoras: o European Research Council, no âmbito do 7.․P Programa-Quadro da União Europeia (FP/2007-2013) // ERC Grant Agreement "Intimate — Citizenship, Care and Choice: The Micropolitics of Intimacy in Southern Europe" (ref. 338452); e a Comissão Europeia ao abrigo do Programa Rights, Equality and Citizenship (ref. 856680), através da agência europeia Norface, via FCT (ref. NORFACE/O001/2016). Pieri deseja reconhecer o apoio concedido pela FCT - Fundação para a Ciência e a Tecnologia (PD/BD/114078/2015).

** Investigadora do Centro de Estudos Sociais da Universidade de Coimbra. E-mail: cristina@ces.uc.pt. ORCID: orcid.org/ 0000-0002-9597-7150.

*** Doutoranda no Centro de Estudos Sociais da Universidade de Coimbra. E-mail: marapieri@ces.uc.pt. ORCID: https://orcid.org/0000-0001-5864-7972
} 
as well as sources of internal conflict that include surrogacy and sex work. In the last section of the paper, we suggest that self-determination is a key concept through which contemporary feminist movements may overcome emerging political and theoretical challenges.

Keywords: collective feminist action; Southern Europe; self-determination.

\section{Introdução}

Este artigo examina a ação coletiva feminista na Itália e em Portugal no século XXI. A escolha dos países baseia-se parcialmente na literatura sociológica existente que constrói o sul da Europa como um contexto geopolítico com características distintas relativamente a regimes de bem-estar e regimes de gênero, quando comparado a outros países europeus (FERREIRA, 2005; TRIFILETTI, 1999; WALBY, 2001). A Europa dos Sul é frequentemente apresentada na literatura como patriarcal, católica, conservadora e familista (FERREIRA, 2005), o que contribui para reforçar uma imagem um tanto homogênea de países como Portugal, Espanha e Itália.

Também na esfera da prestação de cuidado e dos serviços públicos, os países da Europa do Sul são descritos como dispondo de uma forte "sociedade-providência" (SANTOS, 1993), em contraste com a baixa provisão assegurada pelo Estado-providência, característica decorrente da sua posição semiperiférica no sistema mundial, bem como do legado de ditaduras que constam de boa parte da história desses países. Nesse contexto, as mulheres são consideradas um elemento principal da chamada "sociedade-providência" (PORTUGAL, 1998; SANTOS, 1993).

Independentemente de semelhanças sociais e políticas entre países da Europa do Sul, defendemos que uma imagem generalizada desses contextos corre o risco de reforçar estereótipos em vez de os submeter a um questionamento crítico adequado. De fato, a literatura sociológica sobre o sul da Europa tende a descurar diferenças importantes entre países, contribuindo para um imaginário homogêneo, embora precário, acerca do outro. Conscientes dos riscos, neste artigo reconhecemos pontos em comum, ao mesmo tempo que exploramos características específicas da ação coletiva feminista em Itália e em Portugal. Nesse desiderato, serão considerados os contextos históricos, legais e políticos diversos em cada país relativamente à autodeterminação e aos direitos das mulheres. Esse esforço será informado por uma análise sócio-histórica, visando uma melhor compreensão de diferenças e semelhanças entre os dois países.

Esperamos que este artigo contribua para questionar, repensar e reconfigurar teorias contemporâneas sobre regimes de gênero em cada contexto, bem como na Europa do Sul em geral. Ao analisarmos objetivos, 


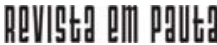

\} RECOLOCANDO A AUTODETERMINAÇÃO - SANTOS, A. C.; PIERI, M. \}

DOI: $10.12957 /$ rep.2021.56089

estra-tégias e resultados dos movimentos de mulheres em Itália e em Portugal, pretendemos ainda contribuir para um conhecimento mais amplo sobre a ação coletiva no século XXI.

\section{Desigualdade de gênero ao longo dos tempos}

Itália e Portugal foram atravessados por longos períodos de ditadura. Em Itália, o regime de Mussolini durou 20 anos (1922-1943); em Portugal, primeiro Salazar e mais tarde Caetano governaram durante 48 anos (1926-1974). A ausência de liberdade e direitos atingia, com maior incidência, setores específicos da população, sendo que as mulheres se encontravam entre os grupos mais penalizados. Em Portugal, as mulheres não tinham permissão para viajar para fora do país ou manter uma conta bancária sem a autorização por escrito do marido, e as mulheres casadas estavam legalmente proibidas de exercer uma profissão que implicasse trabalho noturno.

Essas restrições, entre outras, formaram a espinha dorsal de um regime que considerava "Deus, pátria e família" o modelo tríplice de governação, confundindo religião e política de maneiras que abrangiam todas as dimensões da experiência pública e privada. Durante esse período, expressões de dissidência foram alvo de perseguição e prisão, e comícios ou qualquer outra forma de "reunião de mais de duas pessoas" foram proibidos. Sob tal regime, as únicas formas de ação coletiva não apenas permitidas, mas ativamente encorajas, eram reuniões com fins caritativos ou assembleias religiosas que favoreciam a doutrinação moral incentivada pelo ditador Salazar.

O cenário italiano não é muito diferente nesse sentido. Embora Itália seja uma democracia desde 1946 e, no mesmo, ano o direito universal ao voto também tenha sido concedido, os efeitos das regulamentações fascistas duraram muito tempo. Por exemplo, somente em 1996 a violação deixou de ser crime contra a moralidade pública (como sucedia durante o fascismo) para passar a ser definida por crime contra indivíduos (Lei no 66 , de 15 de fevereiro de 1996). Como em Portugal, em Itália o regime fascista também operava em estreita ligação com instituições católicas, promovendo ideias de mulheres como figuras submissas, cuidadoras e sujeitas aos poderes masculinos da família.

Tal contexto sociocultural restritivo teve um forte impacto nas condições de emergência dos movimentos sociais após a transição democrática. Em Portugal, a pobreza e a raiva foram acompanhadas por elevados níveis de analfabetismo, combatido pelo Poder Executivo eleito. Os movimentos de mulheres, em particular, herdaram as dificuldades cumulativas decorrentes da repressão política e do patriarcado, colocando o sexismo no centro dos problemas socioculturais. A nova Constituição promulgada 


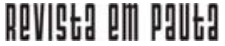

\} RECOLOCANDO A AUTODETERMINAÇÃO - SANTOS, A. C.; PIERI, M.

DOI: $10.12957 /$ rep.2021.56089

em 1976 - a primeira após a mudança para a democracia em 1974 - estabeleceu a igualdade entre mulheres e homens como um princípio central. Esse documento foi celebrado internacionalmente como uma das constituições mais inclusivas do seu tempo.

Estas e outras mudanças legais significativas não apagaram a desigualdade que continuou a caracterizar as vivências íntimas. Por exemplo, a expectativa de que as mulheres sejam as principais prestadoras de cuidados a crianças e pessoas idosas é ainda constitutiva da cultura dominante de prestação de cuidados na Europa do Sul. Essa expectativa decorre de uma cultura de familismo que atribui maiores responsabilidades às famílias nucleares no apoio emocional e financeiro (GONZÁLEZ-LÓPEZ, 2002).

Portanto, já que a igualdade formal não se traduz necessariamente em igualdade de fato, as mulheres e outros grupos identitários cedo se aperceberam da necessidade de ação coletiva, visando denunciar práticas discriminatórias e exigir justiça genuína. Essa transição feminista - que aconteceu em momentos e em ritmos diferentes em Itália e em Portugal - foi acompanhada e apoiada pela entrada na União Europeia (em 1957 como Estado fundador e em 1986, respectivamente). De fato, as políticas de gênero produzidas no nível da UE colocaram pressão no sentido de avanços institucionais para a igualdade de gênero no nível local (estatal), consubstanciando as reivindicações apresentadas pelos movimentos de mulheres.

\section{Itália e Portugal hoje}

Verificam-se elementos recorrentes nos dois países que permitem identificar semelhanças sem ignorar as particularidades de cada contexto. No entanto, a compreensão de aspectos históricos e sociais específicos dos contextos português e italiano é fundamental para situar os movimentos feministas contemporâneos não apenas como experiências especificamente localizadas, mas também em relação às vagas internacionais de ativismo.

Uma característica primordial do contexto contemporâneo é o fato de a Igreja Católica reter um monopólio quase inquestionável em ambos os países. Segundo o Projeto de Futuros Religiosos Globais da Pew-Templeton, $91,9 \%$ das pessoas portuguesas e $83,3 \%$ das pessoas italianas definiram-se em 2017 como católicas ${ }^{1}$. No entanto, os processos de secularização reduziram consistentemente o número de praticantes reais e aumentaram a distância entre a religião católica e uma cultura católica. Segundo o Istat, o Instituto Nacional Italiano de Estatística, em 2016 apenas $29 \%$ da população era católica praticante.

Portanto, se, por um lado, a participação em serviços religiosos diminui a cada ano, a influência das instituições católicas ainda permeia a

${ }^{1}$ Informações disponíveis em: www.globalreligiousfutures.org/. Acesso em: 7 nov. 2020. 
\} RECOLOCANDO A AUTODETERMINAÇÃO - SANTOS, A. C.; PIERI, M. \}

DOI: $10.12957 /$ rep.2021.56089

vida social, política e econômica, principalmente no que diz respeito à regulamentação da cidadania sexual (SANTOS; TOLDY, 2016). A interferência do Vaticano nos debates políticos sobre aborto, direitos LGBT e questões de gênero é consistente e, especialmente em Itália, exerce efetivamente uma influência sobre as políticas internas (GRIGOLO; JORGENS, 2010).

A influência católica em todos os aspectos da vida social estendese também a pessoas não praticantes ou que não são batizadas: em ambos os países há um grande número de escolas e universidades católicas, bancos, fundações, hospitais e casas de repouso. Nos últimos anos, as instituições católicas e movimentos antifeministas canalizaram uma pressão crescente contra a suposta disseminação do que designam por "ideologia de gênero": os movimentos feministas são hoje em dia também confrontados com a acusação de promover uma ideologia perigosa que prejudica crianças e famílias (MAGARAGGIA; VINGELLI, 2015).

Nesse contexto, o sexismo estrutural e a violência contra as mulheres são dois elementos que caracterizam a Itália e o Portugal contemporâneos. De fato, de acordo com o relatório mais recente do Eige - Instituto Europeu para a Igualdade de Gênero ${ }^{2}$ - a disparidade entre mulheres e homens é ainda significativa nos dois países: enquanto as posições de poder são ocupadas principalmente por homens, as mulheres são relegadas a papéis relacionados com cuidado, reprodução e dependência econômica. Por exemplo, as atividades de prestação de cuidado e assistência são desempenhadas principalmente por mulheres, enquanto os níveis de recursos econômicos permanecem fortemente diferenciados. Além disso, o relatório sinaliza que, em 2015, 27\% das italianas e 25\% das portuguesas entrevistadas afirmaram ter sido vítimas de violência sexual, confirmando o sexismo como uma das pragas das sociedades italiana e portuguesa contemporâneas. Não é de surpreender que a maioria das mulheres seja vítima de atos violentos por parte de parceiros, pais, ex-parceiros ou amigos (BETTAGLIO et al., 2018).

Acresce que ambos os países enfrentaram consequências devastadoras da crise econômica global iniciada em 2008. Nos últimos dez anos, as taxas de desemprego, o custo de vida e a insegurança aumentaram, provocando efeitos em cascata entre os grupos mais vulneráveis, em particular as mulheres. Dada a centralidade da família nas culturas portuguesa e italiana, um dos efeitos imprevisíveis da crise foi o regresso de pessoas jovens e jovens famílias à casa parental e, consequentemente, o crescente peso da prestação de cuidados para as mulheres. Ao mesmo tempo, movimentos antiausteridade proliferaram nos dois países.

As duas próximas duas seções concentrar-se-ão nos movimentos de mulheres em Itália e Portugal, com um enfoque duplo nos temas agre-

${ }^{2}$ Disponível em: https://eige.europa.eu/gender-equality-index/2015/domain/violence. Acesso em: 7 nov. 2020. 


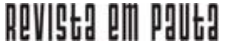

\} RECOLOCANDO A AUTODETERMINAÇÃO - SANTOS, A. C.; PIERI, M.

DOI: $10.12957 /$ rep.2021.56089

gadores, por um lado, e nos tópicos de dissidência, por outro. Ambas as lentes informarão a nossa leitura acerca do papel da autodeterminação como uma demanda política por parte dos movimentos de mulheres.

\section{Ação coletiva feminista no século XXI: temas e repertórios dominantes}

\section{Ação coletiva feminista em Portugal}

Os estudos sobre a ação coletiva feminista em Portugal são unânimes em reconhecer a dificuldade histórica na mobilização social e no lobby político (CAMPOS; AMÂNCIO, 2007; MONTEIRO; FERREIRA, 2012; TAVARES, 2011). Conforme descrito na seção anterior, a ausência de um movimento forte de mulheres pode ser explicada por uma combinação de fatores que incluem pobreza, analfabetismo e sexismo generalizado, ancorados em normas culturais conservadoras. Esses fatores devem ser entendidos no contexto de uma democracia relativamente recente que surgiu após 48 anos de ditadura.

Esta tendência dominante de desmobilização é compensada por momentos de intensa mobilização em torno de tópicos específicos, fato que constitui mais uma exceção do que regra. Apesar de seu caráter excepcional, alguns momentos de intensa mobilização provocaram resultados importantes, principalmente no campo da cidadania reprodutiva. Com efeito, o tema agregador mais significativo da ação coletiva feminista em Portugal é o aborto.

A reivindicação de descriminalização do aborto a pedido da mulher estava na agenda feminista desde os anos 1980, mas o enquadramento jurídico permaneceu restritivo até os anos 2000. No século XXI, a mobilização em torno do aborto pode ser agregada em torno de três momentos principais - o referendo de 1998; a campanha Making Waves em 2004; e o referendo de 2007. Depois de perder o primeiro referendo da história da democracia portuguesa, em 1998, as e os ativistas pró-escolha diversificaram os seus repertórios de ação com forte internacionalização, lobby e ação direta.

Entre 2001 e 2007, registaram-se impressionantes momentos de mobilização de mulheres e pessoas aliadas em protesto à porta de tribunais onde mulheres e profissionais de saúde eram julgados (TAVARES; COVA, 2007). Essas ações atraíram a atenção política e da comunicação social, mas nunca da mesma forma que sucedeu durante a Campanha Fazendo Ondas, em 2004. Essa campanha foi coorganizada por quatro associações locais - a Ação Jovens pela Paz, o Clube Safo, a Não Te Prives e a Umar (União de Mulheres Alternativa e Resposta) - que convidaram a organização holandesa Women on Waves a trazer a Portugal a sua clínica de aborto 


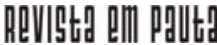

\} RECOLOCANDO A AUTODETERMINAÇÃO - SANTOS, A. C.; PIERI, M.

DOI: $10.12957 /$ rep.2021.56089

instalada num barco. Uma vez dentro do barco, em águas internacionais, as mulheres que desejassem interromper uma gravidez indesejada receberiam a pílula abortiva que o Estado português Ihes recusava. Essa iniciativa despertou uma extraordinária atenção política e midiática a nível nacional e internacional, certamente superior ao impacto sobre o reduzido número de mulheres que a pílula teria sido capaz de ajudar (SANTOS et al., 2010).

A campanha Fazendo Ondas teve dois resultados principais - um deles foi a capacitação de uma nova geração de ativistas que ingressaram na política feminista como jovens voluntárias/os na iniciativa; o segundo resultado foi o fato de a campanha ter conseguido recolocar o aborto na agenda política. Como consequência dessas ações, as leis sobre o aborto mudaram e, desde 2007, as mulheres podem interromper uma gravidez indesejada no serviço nacional de saúde até dez semanas após a gravidez. Esta mudança histórica ocorreu devido à mobilização sem precedentes de mulheres em Portugal em torno de uma única questão.

Entre os temas que despertaram o interesse feminista no século XXI contam-se ainda a violência doméstica, o tráfico de seres humanos e a igualdade formal entre mulheres e homens, incluindo a paridade de gênero e a disparidade salarial. Por mais importantes que sejam no cenário geral da política feminista, esses temas que provocaram mudanças jurídicas e atenção midiática apresentam uma diferença significativa quando comparados ao tema do aborto - a sua construção como um problema social que afetou as mulheres foi conduzida de cima para baixo, através de diretrizes provenientes de organismos europeus e do governo, em vez de emergir de baixo para cima enquanto demanda coletiva. Por outras palavras, os tópicos geraram atenção, mas falharam em tornar-se questões verdadeiramente mobilizadoras equiparáveis ao aborto.

No caso da violência doméstica, apesar da atenção regular da comunicação social, motivada por eventos particularmente chocantes ou sentenças de tribunal sexistas, dois fatos parecem ter contribuído ainda mais para a centralidade do tema. São eles: o financiamento existente para pesquisas sobre violência doméstica no início dos anos 2000 e o Observatório das Mulheres Assassinadas, uma iniciativa da ONG feminista Umar. Em 2004, a organização não governamental começou a coletar anualmente notícias publicadas em jornais nacionais ${ }^{3}$ sobre mulheres assassinadas em Portugal.

Em 2018, um conjunto de protocolos foram assinados entre as autoridades locais e o Estado, reunindo municípios e outros agentes que trabalham contra a violência doméstica. Um dos principais objetivos desses protocolos é desenvolver e consolidar instalações que protegem as mulheres de seus agressores e outros serviços para obter informações, relatórios e aconselhamento jurídico. Com poucas exceções, entre 2000 e 2018, a

${ }_{3}^{3}$ Os relatórios anuais podem ser consultados em: www.umarfeminismos.org/index.php/observatorio-de-mulheresassassinadas. Acesso em: 7 nov. 2020. 


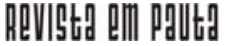

\} RECOLOCANDO A AUTODETERMINAÇÃO - SANTOS, A. C.; PIERI, M.

DOI: $10.12957 /$ rep.2021.56089

questão da violência doméstica permaneceu confinada ao feminismo de Estado e aos serviços de prestação de cuidados, não constituindo um forte mobilizador de baixo para cima para movimentos sociais feministas.

Dito isto, a partir de 2019 o tema adquiriu maior transversalidade social, em paralelo com mobilizações internacionais como o movimento MeToo e Ni Una de Menos. Nas primeiras semanas de 2019, notícias acerca de doze mulheres assassinadas pelos seus companheiros ou ex-companheiros, juntamente com sentenças chocantes e sexistas proferidas pelo juiz Neto de Moura, provocaram um debate social e político intenso, gerando uma onda notável de comoção e uma mobilização de baixo para cima sem precedentes em torno da violência doméstica ${ }^{4}$. O tópico foi importante nas marchas feministas de 8 de março de 2019 que, pela primeira vez na história portuguesa, reuniram centenas de participantes em dez cidades do país, exigindo respeito pelos direitos das mulheres.

Um segundo tema agregador tem sido o tráfico de pessoas, que assumiu grande relevo nos anos 2000, especialmente para o feminismo acadêmico, com vários projetos de investigação financiados para pesquisar no que era até então um campo desconhecido. O feminismo de Estado, especialmente a Comissão para a Cidadania e a Igualdade de Gênero, tem investido na disseminação do conhecimento acadêmico sobre tráfico de pessoas (ALBANO, 2013; SANTOS et al., 2008). O tópico agregou trabalhos acadêmicos numa área ainda pouco desenvolvida dos Estudos de Gênero no contexto português e, consequentemente, motivou intervenções públicas do feminismo de Estado, constituindo uma parte significativa da política feminista no século XXI (OLIVEIRA, 2017). No entanto, não teve um impacto substancial na agenda ou nas práticas dos movimentos de mulheres de base.

O terceiro conjunto de políticas feministas gira em torno da igualdade formal entre mulheres e homens, um dos principais focos da Secretária de Estado para a Cidadania e a Igualdade. A pasta promulgou uma série de medidas legislativas significativas para combater as disparidades salariais entre mulheres e homens e conciliar a vida profissional e a vida pessoal e familiar, especialmente em 2018. Antes disso, as iniciativas mais importantes sobre gênero foram: os Planos Nacionais para a Igualdade, lançados em 1997 e replicados a cada três anos, e a Lei da Paridade, aprovada em 2006 e destinada a garantir níveis equilibrados de participação na vida parlamentar para mulheres e homens. Essas mudanças exemplificam os resultados da intervenção estatal, com órgãos políticos formais como a Secretaria de Estado e a Comissão para a Cidadania e a Igualdade de Gênero a identificar e adotar medidas específicas. Mais uma vez, apesar de fundamentais na vida das mulheres, os empenhos não resultaram de uma ação coletiva de

${ }^{4}$ Ver, por exemplo: www.eurotopics.net/en/216182/portugal-judge-protects-wife-beaters. Acesso em: 7 nov. 2020. 
\} RECOLOCANDO A AUTODETERMINAÇÃO - SANTOS, A. C.; PIERI, M. \}

DOI: $10.12957 /$ rep.2021.56089

base, mas sim da mobilização do que tem sido reconhecido como feminismo de Estado (MONTEIRO; FERREIRA, 2012).

\section{Repertórios feministas em Itália}

A partir dos anos 2000, os movimentos feministas italianos apresentam um ritmo desigual, alternando picos de mobilização em torno de questões específicas com períodos de menor visibilidade. No entanto, estudos sobre mobilização coletiva revelam também um acentuado nível de fragmentação de experiências, tanto geográfica quanto politicamente (BONOMI ROMAGNOLI, 2016).

O século XXI começou de maneira dramática para todos os movimentos coletivos em Itália. Durante o Fórum Social Global e a reunião do G8 em Génova, em 2001, movimentos, coletivos, organizações e indivíduos, inclusive feministas, uniram forças para protestar contra a virada econômica global (DELLA PORTA; REITER, 2006). Todavia, a direção violenta que tomou conta dos eventos, com a morte do ativista Carlo Giuliani e a brutal violência policial contra ativistas em Bolzaneto, teve um impacto em todas as áreas de ativismo. Para o movimento feminista italiano, significou um regresso às práticas separatistas e a ações locais (BONOMI ROMAGNOLI, 2016).

Como no caso de Portugal, a violência de gênero e a proteção do direito ao aborto constituem as questões agregadoras mais relevantes para os movimentos feministas italianos. Estes temas ganharam visibilidade política a partir de 2006, quando a primeira marcha nacional foi organizada em Milão com o nome Usciamo Dal Silenzio (Fora Do Silêncio). Após esse evento, a luta política contra o sexismo institucional e cultural foi propagada e fragmentada em várias experiências que ocuparam o cenário local e nacional com visibilidade quase ininterrupta (BETTAGLIO et al., 2018).

Em 2007, ocorreu outro protesto nacional de massa sob o lema comum Non In Mio Nome (Não Em Meu Nome), para protestar contra a cobertura da imprensa pela violação e assassinato de Patrizia Reggiani por um migrante, no qual o foco político e midiático foi enquadrado em termos de retórica racista em vez do ato de violência de gênero. A questão da representação está de fato consistentemente presente nas demandas nacionais dos movimentos feministas: violência sexual, agressão e sexismo estão ligados à representação decrescente das mulheres nos meios de comunicação social, especialmente na televisão, onde são frequentemente mostradas através de uma lente de objetificação (GRIBALDO; ZAPPERI, 2012).

O vínculo entre a violência simbólica da representação e a mobilização feminista tornou-se particularmente forte durante os anos em que Silvio Berlusconi foi primeiro-ministro (2001-2006 e 2008-2011). A sua dupla posição de chefe de governo e de três canais públicos de televisão, a 


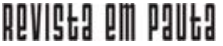

\} RECOLOCANDO A AUTODETERMINAÇÃO - SANTOS, A. C.; PIERI, M.

DOI: $10.12957 /$ rep.2021.56089

frequente objetificação das mulheres nos seus programas de televisão (ZANARDO, 2014), as piadas sexistas nos seus discursos públicos diários e os numerosos escândalos sexuais nos quais estava envolvido, tudo contribuiu para o crescimento do descontentamento coletivo. Durante esses anos, a narrativa dominante em torno das mulheres foi polarizada entre o papel das mães - e uma celebração de sua função reprodutiva - e o papel da beleza, funcional para o desejo masculino. Contudo, a mobilização nesse sentido falhou em incluir interseções com raça e classe, sugerindo uma crítica feminista enraizada numa ideia de normalidade implicitamente branca e de classe média (BONFIGLIOLI, 2010).

O descontentamento atingiu um ponto crítico em 2011, com a mobilização do movimento autoproclamado Se Non Ora Quando? (Quando, Se Não For Agora?). A mobilização produziu um protesto acompanhado por mais de um milhão de pessoas em Roma. Embora os slogans feministas tenham sido diluídos numa forma mais geral de descontentamento público e reivindicações contraditórias de diferentes correntes de ativistas, o protesto produziu consequências relevantes, encorajando uma mudança paradigmática na linguagem usada para definir a violência de gênero.

Graças ao trabalho capilar de jornalistas, figuras públicas de destaque, acadêmicas/os e ativistas, as expressões "tragédia amorosa", "loucura" e "crime passional" foram lentamente substituídas pelas palavras "feminicídio" e "violência de gênero" (BETTAGLIO et al., 2018). No entanto, o movimento também propôs uma visão dicotômica das mulheres entreboas ou más, e as supostamente más, como profissionais do sexo, migrantes e lésbicas, foram excluídas de uma só vez. Essa visão estava de acordo com o retorno neoliberal ao essencialismo de gênero por meio de uma radicalização de conceitos opostos de masculinidade e feminilidade inscritos em discursos de autoempoderamento e agência feminina (GRIBALDO; ZAPPERI, 2012; MCROBBIE, 2012).

Curiosamente, durante esses mesmos anos, o festival feminista Ladyfest em Roma recebeu mais de 7.000 feministas de toda a Europa. O sucesso do festival mostrou que, enquanto um movimento feminista mais mainstream estava orientado para pressões contra instituições, uma vasta gama de coletivos de menor dimensão estava ativa na promoção do ativismo feminista a um nível mais local e alternativo (BONOMI ROMAGNOLI, 2016).

Convém mencionar o papel dos centros e clínicas antiviolência, geralmente autofinanciados e geridos por ativistas. Suas conexões com a rede internacional Wave (Women Against Violence in Europe) foram particularmente influentes naqueles anos, intervindo em áreas em que a regulamentação estatal era vaga ou lenta, bem como demonstrando eficiência na produção de uma rede capilar de segurança para mulheres vítimas de violência.

Em 2016, após a ascensão do movimento argentino Ni Una Menos, que lutava contra o feminicídio no país, o ativismo feminista em Itália teve uma nova onda de participação, através da constituição da rede Non 


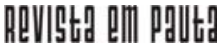

\} RECOLOCANDO A AUTODETERMINAÇÃO - SANTOS, A. C.; PIERI, M. \}

DOI: $10.12957 /$ rep.2021.56089

Una Di Meno (Nudm)5. O movimento incluiu uma ampla gama de assuntos e abriu um espectro de demandas feministas: não apenas sexismo e violência de gênero, mas também precariedade, autodeterminação para todas as muIheres, incluindo mulheres trans e pessoas não binárias, interseccionalidade e acesso à saúde (PERONI, 2018). A ascensão do movimento Nudm sinaliza a necessidade de ação coletiva em relação a questões que extravasam meras reivindicações por igualdade de gênero ou contra o sexismo.

Embora as/os ativistas da Nudm se tenham declarado não institucionais, trabalharam durante dois anos através de assembleias e cmissões auto-organizadas para elaborar um plano nacional contra a violência de gênero que será proposto ao atual governo para enfrentar o problema da violência. Contudo, é digno de nota que o trabalho sobre precariedade foi iniciado anos antes por coletivos interessados nas ligações entre o feminismo e as consequências da crise econômica (BONOMI ROMAGNOLI, 2016; FANTONE, 2007; GALETTO et al., 2007).

O movimento também criou assembleias para discutir questões de educação nas escolas; autodeterminação dos corpos, incluindo questões trans; colaboração com agentes culturais e artísticos; cuidados de saúde; precariedade econômica; cidadania sexual; interseções com as reivindicações das pessoas migrantes; e sexismo dentro dos movimentos sociais, mostrando uma mobilização resiliente e transversal. Talvez seja cedo para entender o impacto do Nudm a nível nacional, mas a natureza multiorientada do movimento sugere que o feminismo italiano está a transformar-se, entrando numa nova fase de ação coletiva.

Parece importante notar que, embora o direito ao aborto tenha sido uma das primeiras conquistas do movimento feminista e esteja garantido pela Lei 194 (aprovada em 1978), a lei tem sido repetidamente visada por diferentes partidos políticos em décadas recentes. A pressão constante do Vaticano e o direito à objeção de consciência de profissionais de saúde criaram um cenário em que o direito ao aborto não é acessível a todas as mulheres em todo o país. Como reação à condição desigual da assistência à saúde, em algumas cidades os coletivos feministas criaram centros clínicos autofinanciados experimentais, chamados de consultorie, que prestam assistência médica e psicológica a vários níveis (BUSI; FIORILLI, 2014). Essas experiências refletem a necessidade de trabalhar em novos entendimentos de bem-estar, autodeterminação e interseccionalidade.

\section{"Guerras feministas": conflitos dentro dos movimentos feministas contemporâneos}

Esta quarta seção investiga o modo como questões específicas constituem poderosos gatilhos de dissidência interna entre movimentos

\footnotetext{
${ }^{5}$ Vide: https://nonunadimeno.wordpress.com/. Acesso em: 7 nov. 2020
} 


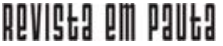

\} RECOLOCANDO A AUTODETERMINAÇÃO - SANTOS, A. C.; PIERI, M.

DOI: $10.12957 /$ rep.2021.56089

feministas e colocam desafios à autodeterminação enquanto reivindicação feminista fundamental. Abre-se o campo para novas práticas de ativismo. No contexto português de política feminista, houve dois focos principais de discordância interna: trabalho sexual e gestação de substituição.

O trabalho sexual tem sido historicamente considerado como violência contra as mulheres e abordado por organizações que visam proteger e "resgatar" as mulheres da prostituição (OLIVEIRA, 2018). Somente em 2004, após o Congresso Feminista Português, as organizações de muIheres começaram a considerar a possibilidade do trabalho sexual como resultado de uma decisão informada e autodeterminada. A organização feminista Umar teve um papel pioneiro a esse respeito, mas o tópico permanece altamente controverso, liderado por ONGs e coletivos de mulheres com uma perspectiva abolicionista que insiste num discurso salvífico.

É o caso de O Ninho, associação cujo trabalho abolicionista foi endossado pelo feminismo de Estado e formalmente reconhecido pela Presidência da República, concedendo-lhe o Prêmio Direitos Humanos (OLIVEIRA, 2017). Essa visão também foi apoiada por partidos políticos de todo o espectro, incluindo parlamentares de esquerda e, talvez mais importante, pela Comissão para a Cidadania e a Igualdade de Gênero (CIG), que definiu a prostituição como uma forma de violência contra as mulheres, uma violação de direitos humanos e uma forma de exploração (CIG, 2014). Na academia portuguesa, o tópico permanece relativamente pouco abordado, talvez como consequência do tabu em torno da autodeterminação das mulheres em relação ao trabalho sexual.

Exceções honrosas podem ser encontradas nas contribuições de Alexandra Oliveira $(2004,2011,2018)$, Manuela Ribeiro (2008) e, mais recentemente, Fernanda Belizário (2019). O trabalho das acadêmicas feministas nessa área do conhecimento é essencial para informar o debate. Num livro fundamental publicado em 2007, reunindo contribuições de mais de 30 estudiosas feministas em Portugal, o trabalho sexual - referido como prostituição - foi incluido entre os tópicos da política feminista do futuro, juntamente com a reprodução medicamente assistida e a masculinidade (JOAQUIM, 2007). Aqui ilustra-se quão recente é o debate, apesar de tão profundamente polarizado.

Um tema ainda mais recente é a gestação de substituição, que começou a ser discutida entre os círculos feministas portugueses em 2016. Tal deveu-se a uma proposta de lei apresentada pelo Partido Socialista e apoiada pelo Bloco de Esquerda, os Verdes e o PAN (Partido Pessoas-Animais-Natureza), que abordou a reprodução medicamente assistida e a gestação de substituição como direitos reprodutivos. Um dia após a lei ter sido aprovada no Parlamento, em maio de 2016, a Plataforma Portuguesa para os Direitos das Mulheres emitiu uma declaração na qual expressava sérias preocupações sobre o potencial presumivelmente explorador e violento de gestação de substituição nos corpos e na autonomia das mulheres: 
Que apoio podemos dar à gestação de substituição considerando que os riscos da institucionalização e mercantilização desta prática são reais e constituem uma violação dos direitos humanos de todas as mulheres? A exploração dos corpos das mulheres em geral - por via da prostituição, da pornografia, da exploração sexual, de representações híper-sexualizadas dos corpos das mulheres e da objetivação sexual, da sexualização precoce, etc. - e dos seus órgãos reprodutivos em particular, não pode ser tolerada, legalizada nem regulamentada em Estados que se proclamam democráticos e defensores dos direitos humanos! (PPDM, 2016).

A gestação de substituição é uma das raras questões em que os partidos de direita e de esquerda no Parlamento português parecem concordar unanimemente. Curiosamente, o Partido Comunista Português (2016) - um aliado histórico dos direitos das mulheres em Portugal - votou por unanimidade contra a gestação de substituição. Convém mencionar aqui o enriquecedor trabalho de Pérez Navarro (2018) sobre gestação de substituição no contexto do sul da Europa, em particular na Espanha.

Como é o caso noutros contextos, particularmente na Europa do Sul a partir de 2016, as posições feministas contra a gestação de substituição assemelham-se ao discurso abolicionista, na medida em que se recusam a respeitar as mulheres - gestantes e profissionais do sexo, respectivamente e suas demandas em torno da autodeterminação e do direito à escolha. Voltaremos a esse ponto mais adiante neste artigo. Mas, por enquanto, parece importante notar que as divisões dentro dos movimentos de mulheres em Portugal não seguem um padrão regular e linear baseado em diferenças geracionais; pelo contrário, a controvérsia, mas também os momentos de intensa mobilização são animados por mulheres ao longo de todo o espectro geracional, desde coletivos informais de jovens às militantes mais experientes que representam a resistência à opressão fascista e foram pioneiras na ação coletiva feminista em Portugal. As políticas partidárias que informam a militância feminista parecem desempenhar um papel mais decisivo quando se trata de enquadrar o trabalho sexual e a gestação de substituição enquanto exploração neoliberal ou enquanto trabalho (sexual ou reprodutivo) escolhido.

Ao contrário de Portugal, em Itália a grande diferença entre gerações de feminismo - as chamadas "guerras feministas" (CRISPINO, 2018) - representa a principal fonte de conflitos internos dentro dos movimentos. De um lado, a presença de uma geração mais antiga de feminismo, ligada à segunda vaga do movimento, ainda é relevante (BRACKE, 2014). Essa geração envolveu-se em lutas pelo direito ao divórcio, aborto e reconhecimento da violação como crime durante os anos 1970, 1980 e parte dos anos 1990. Partindo da teoria da diferença sexual (IRIGARAY, 1984), essa corrente de ativismo estava ligada a uma visão essencialista de gênero, reivindicações sobre a especificidade das mulheres e práticas separatistas. 


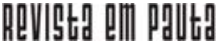

\} RECOLOCANDO A AUTODETERMINAÇÃO - SANTOS, A. C.; PIERI, M.

DOI: $10.12957 /$ rep.2021.56089

Além disso, foi caracterizada pela fragmentação em vários grupos locais de menor dimensão, com base em práticas de autorreflexão (FANTONE, 2007). Hoje, um grande número de ativistas (especialmente as mais velhas) ainda está conectado a essas reivindicações e práticas. As suas posições essencialistas são contra o trabalho sexual, transfóbicas e críticas a práticas como a gestação de substituição. Por outro lado, as gerações mais jovens, muitas vezes identificadas por "a terceira vaga do feminismo", cresceram num contexto de feminismo difuso, no qual alguns direitos básicos estavam já garantidos (MAGARAGGIA; VINGELLI, 2015).

Graças ao encontro com teorias queer nos contextos acadêmicos e no ativismo, prevaleceram as abordagens transfeministas e descoloniais da ação coletiva, com interesse em subverter categorias estáveis e normalizadas em favor de interpretações fluidas e interseccionais de gênero e identidade. A terceira vaga demonstrou um compromisso com a prática do feminismo de maneira interseccional, em estreita conexão com questões de precariedade, sexualidade e racismo. Além disso, a familiaridade com as novas tecnologias e a ligação a redes internacionais incentivaram estratégias de ação que envolvem redes sociais, performatividade e um uso subversivo das tecnologias de comunicação (PERONI, 2018).

Como no caso de Portugal, a questão do trabalho sexual permanece altamente conflitual nos movimentos feministas italianos. Enquanto as feministas da segunda vaga viam tradicionalmente o trabalho sexual como uma extensão da dominação patriarcal sobre os corpos das mulheres, em tempos recentes as feministas apoiaram posições que distinguem entre trabalho sexual como uma escolha livre e tráfico ou exploração (PERONI, 2012; SERUGHETTI, 2017). Além disso, o ativismo queer e o transfeminismo contribuíram para lançar uma nova luz sobre a/o profissional do sexo como pessoa autodeterminada e incluí-la na mesma figuração política de lésbicas, gays, queers e pessoas trans. No processo de reivindicar a centralidade da autodeterminação e a importância de subverter as representações normativas, as transfeministas também se engajaram numa crítica da indústria pornô normativa, incentivando diferentes representações através de festivais e workshops em pós-pornografia (BETTAGLIO et al., 2018).

O conflito geracional dentro dos feminismos também parecia bastante severo no que diz respeito à gestação de substituição. Em Itália, embora exista uma lei que proíbe a gestação de substituição desde 2004, o debate alcançou um novo pico de visibilidade pública entre 2015 e 2016, quando a Lei Cirinnà foi discutida no Parlamento (COSSUTTA, 2018; MOTTERLE; GUERZONI, 2018). Essa lei destinava-se a regular as uniões civis do mesmo sexo e continha um parágrafo referente à possibilidade de coadoção. Pela identificação da maternidade com a gravidez, as feministas da segunda vaga classificaram as gestantes como vítimas da exploração neoliberal e da exploração do corpo das mulheres pelos homens (MURARO, 2016). 
Essas posições geraram alianças inesperadas entre essa parte dos movimentos feministas e grupos radicais de direita e ultracatólicos. A principal organização nacional de lésbicas, Arcilesbica, endossou essa perspectiva, abrindo uma profunda crise no movimento LGBT. No lado oposto, transfeministas e coletivos queer apoiaram a necessidade de um debate sobre a gestação de substituição que garantiria que casais não heterossexuais tivessem acesso à parentalidade sem discriminação.

No entanto, o debate foi tão polarizado que, mesmo após a aprovação da Lei Cirinnà em fevereiro de 2016 (e a parte da coadoção removida da versão final), a fratura não sarou e a questão da gestação de substituição ainda gera divisões dentro e fora dos movimentos feministas. O conflito geracional, que opõe diferentes maneiras de pensar e praticar o feminismo, mais do que apenas gerações baseadas no gênero, parece estar destinado a criar conflitos dentro dos movimentos sempre que diferentes compreensões de autodeterminação, ação coletiva e, finalmente, o significado de mulher são postas em causa por razões políticas.

\section{Recolocando a autodeterminação na equação: notas finais sobre os desafios aos movimentos feministas hoje}

A autodeterminação sempre foi uma reivindicação feminista central. $\mathrm{O}$ que se perde quando a autodeterminação é questionada e o feminismo dominante (de Estado) obscurece tudo o que é matizado e potencialmente perturbador? Onde está o lugar para a ação nos modelos de ação coletiva autorizada pelo feminismo de Estado? Ủma das lições que o feminismo retirou da sua experiência política é que o gênero e a sexualidade foram sempre tratados como secundários por outros militantes que não tardam em produzir hierarquias de prioridade que invariavelmente empurram as demandas feministas para o fim da agenda.

Foi necessário esforço e muito conflito interno para que as muIheres recusassem o paternalismo e outras formas de menorização em fóruns de discussão e construção de políticas para inclusão, igualdade e diversidade. Na Europa do Sul, como noutros contextos, é necessário um esforço diário para garantir o respeito por direitos já alcançados (ainda que precariamente) e para evitar reações adversas em tópicos tão básicos quanto a linguagem inclusiva e o combate à cultura da violação. Foi através da política feminista que aprendemos a enquadrar a agência enquanto "meu corpo, minhas regras" e que, portanto, a autodefinição era primordial - "não é não", como diria hoje qualquer militante contra o assédio e outras formas de violência de gênero.

Dada essa premissa fundamental, reconhecer que os limites à autodeterminação que colocam em causa reivindicações das mulheres acerca do seu próprio corpo e experiência estão a ser promovidos por movimentos de mulheres, apresenta enormes desafios ao trabalho acadêmico 


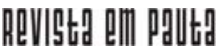

\} RECOLOCANDO A AUTODETERMINAÇÃO - SANTOS, A. C.; PIERI, M. \}

DOI: $10.12957 /$ rep.2021.56089

feminista no momento atual. A contradição está instalada entre os movimentos das mulheres, com expressões crescentes em todo o mundo: mulheres contra o trabalho sexual, mulheres contra a gestação de substituição, mulheres contra mulheres que denunciam seus agressores, mulheres cisgênero contra mulheres trans, para citar apenas alguns casos.

Estes e outros exemplos de dissidência dentro da política feminista sublinham os limites à autodeterminação que são impostos não a partir do exterior, por parte de partidos conservadores ou outros agentes patriarcais, mas por autodesignados movimentos feministas no século XXI. Isso coloca um novo conjunto de perguntas, convidando as acadêmicas a encontrar novas maneiras de teorizar e praticar a política feminista.

Diante de velhos e novos desafios para mobilizar mulheres através de temas unificadores, paralelamente ao aumento de divisões dentro de um movimento social já vulnerável, a política feminista nos dois países desenvolveu estratégias ajustadas para a sobrevivência. Um aspecto mais significativo da política feminista da Europa do Sul no século XXI é a interseccionalidade. A pertença múltipla corporizada - ainda que parcial e insuficiente - tornou-se o fundamento legítimo para exigir visibilidade e justiça. Em Portugal, a virada interseccional feminista remonta a 2015 e agregou mulheres negras lutando contra o heterossexismo, racismo e precariedade. Exemplos de intervenção por parte do feminismo negro incluem o blog Queering Style (2015), o Coletivo Zanele Muholi de Lésbicas e Bissexuais Negras (2016), a Femafro - Associação de Mulheres Negras, Africanas e Afrodescendentes (2016) e o Inmune - Instituto da Mulher Negra (2018) (ROLDÃO, 2019).

Além disso, o feminismo de Estado tem assumido cada vez mais a necessidade de pensar e agir transversalmente sobre as identidades, e as iniciativas da Secretária de Estado para a Cidadania e a Igualdade de Gênero desde 2015 denotam preocupações interseccionais, agregando questões feministas e LGBTQI+ em documentos oficiais como a Estratégia Nacional para Igualdade e Não Discriminação 2018-2030 (o documento completo pode ser obtido no site oficial do governo português). Paralelamente às questões LGBTQI+, o feminismo de Estado em Portugal está a dar os primeiros passos para colmatar uma histórica lacuna racial, reconhecendo, por exemplo, o papel das mulheres ciganas como agentes-chave no empoderamento e na mudança. É necessário investir muito mais nesse campo para garantir um desenvolvimento sustentado de expectativas e avanços.

Outra característica importante do ajuste estratégico do ativismo feminista nos dois países tem sido a internacionalização. O trabalho em torno da Greve Feminista Internacional demonstra o modo como a solidariedade além-fronteiras se vem desenvolvendo em tempos recentes. Certamente não será o único exemplo de trocas e aprendizagens recíprocas internacionais que ultrapassam com sucesso a distância entre países e continentes, com ênfase na ligação entre o sul da Europa e a América Latina. O 
\} RECOLOCANDO A AUTODETERMINAÇÃO - SANTOS, A. C.; PIERI, M. \}

DOI: $10.12957 /$ rep.2021.56089

transfeminismo, por exemplo, é em grande parte resultado do trabalho realizado por mulheres em trânsito, frequentemente desenvolvido em coletivos informais dinamizados por estudantes internacionais que carregam consigo debates, preocupações e práticas que não são específicas de um determinado contexto. Nesse sentido, quanto mais amplo for a situação, mais rica ela se torna.

Evidentemente, ajustes estratégicos que colocam a autodeterminação de volta à equação concederam aos movimentos das mulheres italiano e português a oportunidade de prosperar em circunstâncias históricas difíceis, conforme procuramos explorar neste artigo. No entanto, os movimentos enfrentam hoje desafios que requerem atenção política e acadêmica. Para concluir, identificamos alguns desses desafios.

Primeiro, o caminho para descolonizar o feminismo e promover a interseccionalidade, incluindo, por exemplo, a capacidade física, o enveIhecimento e as vozes das pessoas migrantes (BERNACCHI, 2017), ainda é longo. Em segundo lugar, reconhecemos o perigo do que poderia ser rotulado como uma versão pop do feminismo, esvaziada de seu conteúdo político e poder coletivo, ligada a uma imagem glamorosa e neoliberal de selfmade. Finalmente, e porventura mais premente, regista-se o risco de retrocesso associado à ascensão da direita e do populismo.

Um efeito já observável nos movimentos antigênero, especialmente na área da educação, cujas ações têm vindo a ocupar debates locais e nacionais desde o início do século, tendo atingido um pico nos últimos cinco anos. As autoridades do Vaticano, primeiro com o Papa Bento XVI, depois com o Papa Francisco I, referem-se repetidamente à alegada existência de uma ideologia de gênero, que constituiria um poderoso instrumento de subversão da ordem natural entre homens e mulheres.

A cruzada antigênero assumiu várias formas, desde a mobilização dos chamados "sentinelas em pé" até o cancelamento de programas de educação sexual nas escolas. Com base em noções inadequadas e confusas de orientação sexual, gênero e sexualidade, as ideias antigênero foram prontamente apropriadas por partidos populistas, resultando numa onda de violência sexista e homofóbica a partir de 2017.

As experiências como Progetto Alice ${ }^{6}$ em Itália, por exemplo, mostram que é necessário trabalhar na construção de um paradigma cultural diferente, almejando criar novas gerações de feministas (homens e mulheres), abertas a diferentes orientações sexuais e identidades de gênero, e conscientes das múltiplas interseções de discriminação e violência. Diante dos desafios atuais e os de um futuro próximo, os movimentos feministas necessitam conceber novas práticas e interseções que coloquem a autodeterminação num lugar central, permanecendo assim agentes incontornáveis da luta coletiva por justiça social.

${ }^{6}$ Para mais detalhes, ver: https://ilprogettoalice.wordpress.com/. Acesso em: 7 nov. 2020. 


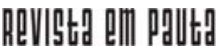

\} RECOLOCANDO A AUTODETERMINAÇÃO - SANTOS, A. C.; PIERI, M. \}

DOI: $10.12957 /$ rep.2021.56089

\section{Referências}

ALBANO, M. Tráfico de seres humanos: a escravatura dos tempos modernos. Notícias CIG, Lisboa, n. 89, 2013.

CAMPOS, A.; AMANCIO, L. O longo caminho das mulheres: feminismos 80 anos depois. Lisboa: Publicac'oPes Dom Quixote, 2007.

BELIZÁRIO, F. Travestis brasileiras no sul da Europa: subalternidade e reconhecimento nas fronteiras do gênero e sexualidade. Tese (Doutorado em Poscolonialismos e Cidadania Global) - Feuc, Universidade de Coimbra, Coimbra, 2019.

BERNACCHI, E. Dynamics of identity and otherness within intercultural feminist practices in Italy. Identities, n. 24, v. 4, maio 2017.

BETTAGLIO, M.; MANDOLINI, N.; ROSS, S. Rappresentare la violenza di genere. Sguardi femministi tra critica, attivismo e scrittura. Milão: Mimesis, 2018.

BONFIGLIOLI, C. Intersections of racism and sexism in contemporary Italy: a critical cartography of recent feminist debate. Dark Matter, out. 2010. Disponível em: http://www.darkmatter101.org/site/2010/10/10/interse ctions-of-racism-and-sexism-in-contemporary-italy-a-critical-cartographyof-recent-feminist-debates/\#foot_src_7. Acesso em: 30 maio 2018.

BONOMI ROMAGNOLI, B. Irriverenti e libere: Femminismi nel nuovo millennio. Roma: Editori internazionali riuniti, 2016.

BRACKE, M. A. Women and the reinvention of the political: Feminism in Italy, 1968-1983. Nova York: Routledge, 2014.

BUSI, B.; FIORILLI, O. Introduzione. Per una prospettiva (trans)femminista sulla salute ai tempi del neoliberismo. DWF - Donne Women Femmes, v. 3-4, n. 103-104, jul. 2014.

CIG. Igualdade de gênero em Portugal, 2014. Disponível em: https://www. cig.gov.pt/wp-content/uploads/2016/03/Igualdade-de-G\%C3\%A9nero-emPortugal-2014.pdf. Acesso em: 30 dez. 2018.

COSSUTTA, C. Maternal relations, feminism and surrogate motherhood in the Italian context. Modern Italy, v. 2, n. 23, 2018.

CRISPINO, A. Introduzione. Leggendaria, v. 128, 2018.

DELLA PORTA, D.; REITER, H. The policing of global protest: the G8 at Genoa and its aftermath. In: DELLA PORTA, D.; REITER, H.; PETERSON, A. (Org.). The policing of transnational protest. Aldershot: Ashgate, 2006.

FANTONE, L. Precarious changes: gender and generational politics in contemporary Italy. Feminist Review, v. 1, n. 87, 2007. 
FERREIRA, M. Welfare state reform in Southern Europe: fighting poverty and social exclusion in Italy, Spain, Portugal and Greece. Londres: Routledge, 2005.

GALETTO, M.; LASALA, C.; MAGARAGGIA, S.; MARTUCCI, C.; ONORI, E.; POZZI, F. A snapshot of precariousness: Voices, perspectives, dialogues. Feminist Review, v. 1, n. 87, 2007.

GONZÁLEZ-LÓPEZ, M. A portrait of western families. New models of intimate relationships and the timing of life events. In: CARLING, A.; DUNCAN, S.; EDWARDS, R. (Org.). Analysing families morality and rationality in policy and practice. Londres: Routledge, 2002.

GRIBALDO, A.; ZAPPERI, G. Lo schermo del potere: femminismo e regime della visibilital. Verona: Ombre Corte, 2012.

GRIGOLO, M.; JORGENS, F. Italy. In: Stewart, C. (Org.). LGBT issues worldwide. Santa Barbara: Greenwood, 2010.

IRIGARAY, L. An ethics of sexual difference. Londres: Continuum, 1984.

JOAQUIM, T. Feminismos, estudos sobre as mulheres ou "para onde vai este barco"? In: CAMPOS, A.; AMÂNCIO, L. (Org.). O longo caminho das mulheres. Feminismos 80 anos depois. Lisboa: Publicac'oPes Dom Quixote, 2007.

MAGARAGGIA, S.; VINGELLI, G. Genere e partecipazione politica. Milão: FrancoAngeli, 2015.

MCROBBIE, A. The aftermath of feminism: gender, culture and social change. Londres: Sage, 2012.

MONTEIRO, R.; FERREIRA, V. Metamorfoses das relações entre o Estado e os movimentos de mulheres em Portugal: entre a institucionalização e a autonomia. Revista Ex Aequo, n. 25, 2012.

MOTTERLE, T.; GUERZONI, C. Sul corpo delle surrogate. Analisi del discorso pubblico italiano sulla gestazione per altri. Gender/Sexuality/Italy, n. 5, 2018.

MURARO, L. L'anima del corpo: contro I'utero in affitto. Milão: La Scuola, 2016.

OLIVEIRA, A. História jurídico-legislativa da prostituição em Portugal. Revista do Ministério Público, n. 98, 2004.

OLIVEIRA, A. Andar na vida. Prostituição de rua e reacção social. Coimbra: Almedina, 2011.

OLIVEIRA, A. Prostituição em Portugal. Uma atividade marginalizada num país que tolera mais do que persegue. Bagoas, n. 17, 2017.

OLIVEIRA, A. Portugal. In: JAHNSEN, S.; WAGENAAR, H. (Org.). Assessing prostitution policies in Europe. Londres: Routledge, 2018. 


\section{ReVIIStR PMI PIUtI}

\} RECOLOCANDO A AUTODETERMINAÇÃO - SANTOS, A. C.; PIERI, M.

DOI: $10.12957 /$ rep.2021.56089

PARTIDO COMUNISTA PORTUGUÊS. Projeto de Lei Gestação de Substituição. 2016. Disponível em: http://bit.do/fFGmj. Acesso em: 7 nov. 2020. PÉREZ NAVARRO, P. Surrogacy Wars: Notes for a Radical Theory of the Politics of Reproduction. Journal of Homosexuality, v. 67, n. 5, 2018.

PERONI, C. Violenza di genere e prostituzione. Norme, controllo, sessualità. In: SIMONE, A. (Org.). Sessismo Democratico. L'uso strumentale delle donne nel neoliberismo. Milão: Mimesis, 2012.

PERONI, C. II \#MeToo di Hollywood e il \#WeTogether di Non Una di Meno. Dalla denuncia alla pratica collettiva contro le molestie sessuali nel/ del lavoro. In: BETTAGLIO, M.; MANDOLINI, N.; ROSS, S. (Org.). Rappresentare la violenza di genere. Sguardi femministi tra critica, attivismo e scrittura. Milão: Mimesis, 2018.

PORTUGAL, S. Women, childcare and social networks. In: FERREIRA, V.; TAVARES, T.; PORTUGAL, S. (Org.). Shifting bonds, shifting bounds. Women, mobility and citizenship in Europe. Oeiras: Celta, 1998.

PPDM. PMA e gestação de substituição e quando a direita e a esquerda partidárias se unem pelos direitos das mulheres. 14 maio 2016. Disponível em: https://plataformamulheres.org.pt/pma-e-gestacao-de-substituicao-equando-a-direita-e-a-esquerda-partidarias-se-unem-pelos-direitos-dasmulheres/. Acesso em: 7 nov. 2020.

RIBEIRO, M. Vidas na raia. Prostituição feminina em regiões de fronteira. Porto: Afrontamento, 2008.

ROLDÃO, C. Feminismo negro em Portugal: falta contar-nos. 18 jan. 2019. Disponível em: www.publico.pt/2019/01/18/culturaipsilon/noticia/fe minismo-negro-portugal-falta-contarnos-1857501. Acesso em: 7 nov. 2020.

SANTOS, A.; TOLDY, T. Religião, gênero e cidadania sexual: uma introdução. Revista Crítica de Ciências Sociais, n. 110, 2016.

SANTOS, B.; SANTOS, A.; DUARTE, M. Cometi um crime? Representações sobre a (i)legalidade do aborto. Porto: Edições Afrontamento, 2010.

SANTOS, B.; GOMES, C.; DUARTE, M.; BAGANHA, I. Tráfico de mulheres em Portugal para fins de exploração sexual. Lisboa: CIG, 2008.

SANTOS, B. O Estado, as relações salariais e o bem-estar social na semiperiferia: o caso português. In: SANTOS, B. Portugal: um retrato singular. Porto: Edições Afrontamento, 1993.

SERUGHETTI, G. Prostituirsi: scelta o costrizione? Il Mulino - Rivista bimestrale di cultura e di politica, n. 4, 2017.

TAVARES, M. Feminismos: percursos e desafios (1947-2007). Texto Editora, 2011. 


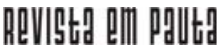

\} RECOLOCANDO A AUTODETERMINAÇÃO - SANTOS, A. C.; PIERI, M. \}

DOI: $10.12957 /$ rep.2021.56089

TAVARES, M.; COVA, A. Aborto e contracepção em Portugal. Lisboa: Livros Horizonte, 2007.

TRIFILETTI, R. Southern European welfare regimes and the worsening position of women. Journal of European Social Policy, v.1, n. 9, 1999.

WALBY, S. From gendered welfare state to gender regimes: national differences, convergence or re-structuring? In: GENDER AND SOCIETY GROUP. Artigo. Estocolmo: Universidade de Estocolmo, 2001. Disponível em: http:/ /www.sociology.su.se/cgs/Walbypaper.doc. Acesso em: 30 dez. 2018.

ZANARDO, L. Il corpo delle donne. Milão: Feltrinelli, 2014.

DOI: $10.12957 /$ rep.2021.56089

Recebido em 22 de junho de 2020.

Aprovado para publicação em 15 de julho de 2020.

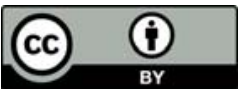

A Revista Em Pauta: Teoria Social e Realidade Contemporânea está licenciada com uma Licença Creative Commons Atribuição 4.0 Internacional. 